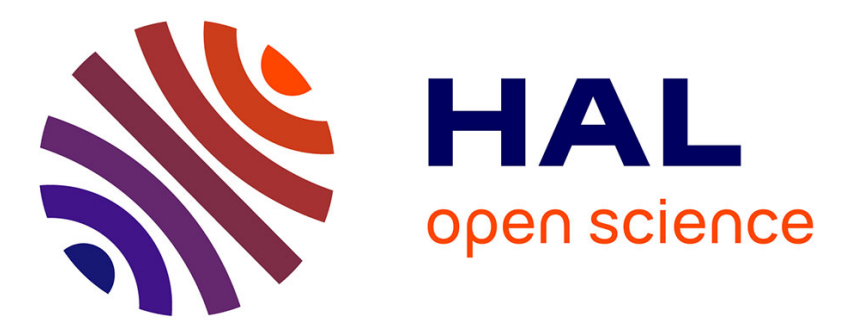

\title{
Social Network Analysis of a Supply Network Structural Investigation of the South Korean Automotive Industry
}

Jin-Baek Kim

\section{To cite this version:}

Jin-Baek Kim. Social Network Analysis of a Supply Network Structural Investigation of the South Korean Automotive Industry. IFIP International Conference on Advances in Production Management Systems (APMS), Sep 2015, Tokyo, Japan. pp.332-339, 10.1007/978-3-319-22756-6_41 . hal01417503

\section{HAL Id: hal-01417503 \\ https://hal.science/hal-01417503}

Submitted on 15 Dec 2016

HAL is a multi-disciplinary open access archive for the deposit and dissemination of scientific research documents, whether they are published or not. The documents may come from teaching and research institutions in France or abroad, or from public or private research centers.
L'archive ouverte pluridisciplinaire HAL, est destinée au dépôt et à la diffusion de documents scientifiques de niveau recherche, publiés ou non, émanant des établissements d'enseignement et de recherche français ou étrangers, des laboratoires publics ou privés. 


\title{
Social Network Analysis of a Supply Network Structural Investigation of the South Korean Automotive Industry
}

\author{
Jin-Baek Kim \\ Chung-Ang University, Business School, 84 Heukseok-ro, Dongjak-gu, Seoul, Korea \\ jinbaek@cau.ac.kr
}

\begin{abstract}
In this paper, we analyzed the structure of the South Korean automotive industry using social network analysis (SNA) metrics. Based on the data collected from 275 companies, a social network model of the supply network was constructed. Centrality measures in the SNA field were used to interpret the result and identify key companies. The results show that SNA metrics can be useful to understand the structure of a supply network. The most significant contribution of this research is that this is the first trial on applying SNA methods to large scale supply networks for an entire automotive industry of a country.
\end{abstract}

Keywords: supply chain, supply network, social network analysis, the South Korean automotive industry

\section{Introduction}

Many studies on supply chains investigated linear relationships between supplying and buying companies, by adopting the perspective of hierarchical value chains. However, the companies constituting a supply chain usually belong to supply chains of other companies and commonly have relationships with other companies. Hence, by adopting a network perspective on supply chains or considering supply networks rather than supply chains, one can better understand the supply chain structure of a company or an industry[4,9,13,14,15,17].

Social network analysis (SNA) methods have been used to study the structure of societies and to identify important entities in a society. If supply chains are modeled as a network, then SNA methods can be useful tools for analysis. Borgatti and Li [2] argued that SNA concepts are particularly useful to identify the patterns of inter-firm relationships in a supply network that lead to competitive advantages through the diffusion of information and management of material flows. Choi and Kim [6] pointed out that SNA methods can complement the traditional perspective on supply chain by capturing the complexity needed to understand a company's strategy or behavior.

Although the potential has been recognized [1,2,3], there are still relatively few empirical studies on real-world supply networks using SNA methods [11]. One reason for that is the difficulty in obtaining comprehensive information on supply chain adfa, p. 1, 2011.

(c) Springer-Verlag Berlin Heidelberg 2011 
relationships among companies, which is necessary to construct a complete social network. Another reason is because SNA methods are oriented to analyzing societies not companies working in the supply chain. Social network analysis theory and the way of interpreting results in sociology cannot be directly applied to the supply chain context. In this study, we used data from Korean Auto Industries Cooperative Association (KAICA) to construct a social network representing the supply network structure of the South Korean automotive industry. The KAICA is a non-profit organization, founded in 1962, to develop the South Korean automotive industry. Most major companies in auto parts and components manufacturing industries operating in Korea are KAICA members. The KAICA collects data every year from its members on their major customers. The data used in this paper is customer information from 275 member companies of KAICA for 2013.

The constructed supply network was analyzed based on centrality metrics. Kim et al. [11] proposed a theoretical framework that links widely used social network metrics to supply network constructs based on the insight earned from case-based interpretations [5]. One conclusion from that study is that the framework can both supplement and complement case-based analysis of supply networks. However, the conclusion was based on an application to small scale supply networks (less than 50 companies) of a part of an automotive supply chain(final assembly). In this study, a relatively large scale supply network (close to 400 companies) was constructed and analyzed, based on social network analysis metrics. A more comprehensive supply network model provides an opportunity to further validate the theoretical framework but also creates challenges in applying the theory. In this study, we focused on validating and extending the theory, although we referred to Kim et al. [11]'s framework to interpret SNA metrics in the supply networks.

\section{About the South Korean Automotive Industry}

As of 2013, there are five major auto makers producing cars in South Korea. They are Hyundai Motor, Kia Motor, Korea GM, SsangYong Motor, and Renault-Samsung Motors. In 2013, the Hyundai-Kia Motor Group produced 3.451 million cars, which corresponds to $76 \%$ of total cars produced in South Korea[10]. GM Korea, SsangYong, and Renault-Samsung accounted for $15.1 \%, 6.4 \%$, and $6 \%$, respectively, of domestic automobile production. The number of cars produced and sold in South Korea by these five companies is shown in Fig. 1. As can be seen, all five auto makers produce more than they sell in South Korea and thus export cars overseas.

Hyundai and Kia Motor have supply chains that are vertically integrated by companies belonging to the group. Key suppliers of Hyundai and Kia Motor are Hyundai Mobis, which provides key module and system components, Hyundai Dymos supplying power train components; Hyundai Powertech supplying transmission components; Hyundai Wia supplying engine and transmission components; and Hyundai Steel providing steel 
material. These Hyundai-Kia Motor Group companies are under the command of a group chairman.

GM Korea, which was formerly Daewoo Motors, has been owned by GM since 2002, while Korea Development Bank (KDB) who participated in the restoration of the bankrupt company also owns $17.02 \%$ of the shares. The ownership of SsangYong Motor has changed hands many times, originally from the Ssangyong Group to the Daewoo Group (1997), and to SAIC (2002). Since 2011, the Mahindra Group is the majority shareholders (72.85\%) of SsangYong Motor. SsangYong's strength has been in the SUV segment and historically had close ties with technologies and supply chains of Daimler AG. Renault-Samsung Motors was originally founded by the Samsung Group in collaboration with Nissan Motor in 1995. Since 2000, it is a part of the Renault Group, which owns 79.88\% share of Renault-Samsung Motors. Samsung Credit Card Co. also owns a $19.9 \%$ share of Renault-Samsung.

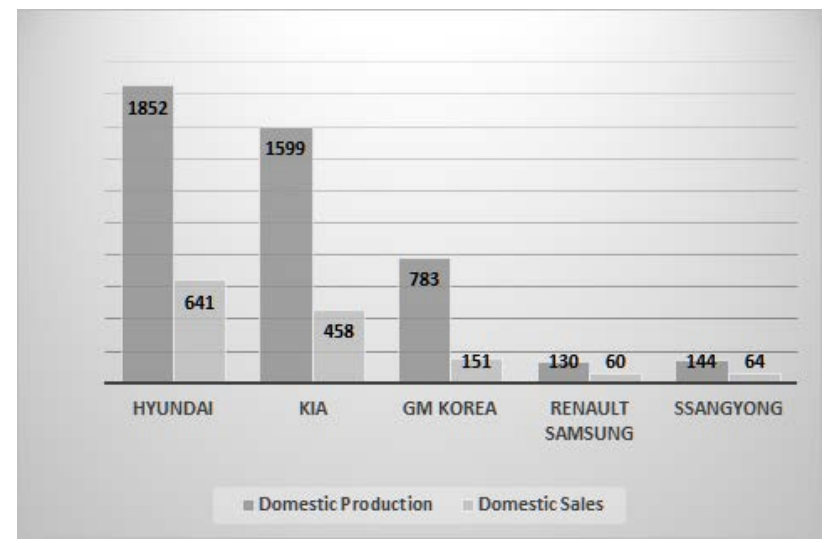

Fig. 1. Domestic production and sales by auto makers in South Korea as of 2013(thousand units) [10]

\section{Analysis of the South Korean Automotive Supply Network Using Social Network Analysis Metrics}

When building a social network model, relationships between entities may be modeled as directed or undirected links. Kim et al. [11] suggested that directed links are useful to describe material flows, whereas undirected links are helpful when examining contractual relationships or information flow. In this study, the supply network was modeled as both directed and undirected networks, and was investigated to understand the material flows and information flows in the supply network.

The constructed supply network was analyzed using Gephi 0.8.2, an open source software for social network analysis. The visual representation of the supply network can be seen in Fig. 2.. That graph is composed of 395 companies, including 285 KAICA 
member companies and their customers who may or may not be KAICA members.

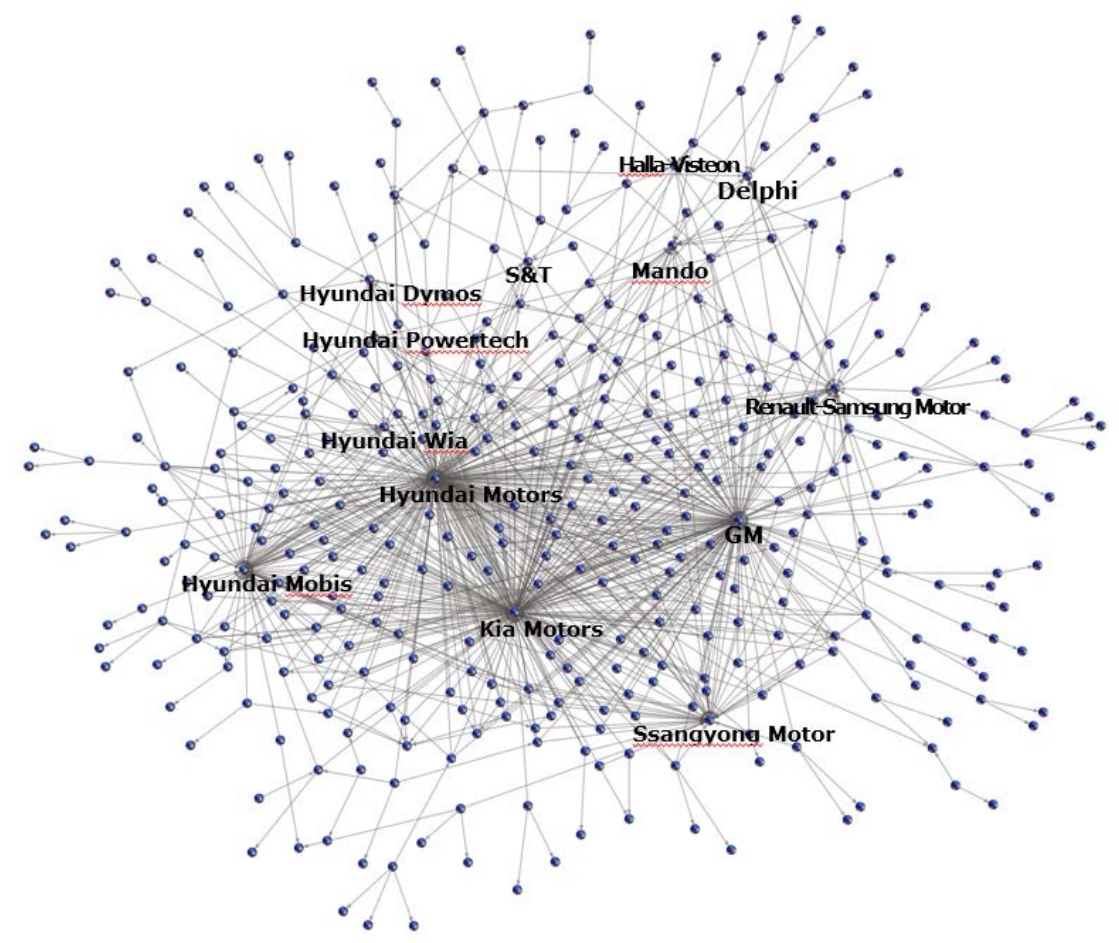

Fig. 2. Visual representation of the South Korean automotive industry supply network

As stated in the previous section, the auto makers play central roles in the South Korean automotive industry. Among the first tier suppliers of the auto-makers, technology and capital intensive parts, such as engine and power train components are provided by the large-sized companies of a group, and parts requiring precision engineering, such as casted/forged parts, are supplied by medium-sized independent companies having close ties with auto-makers. The second-tier suppliers providing commodity like parts, such as iron rods, bolts, nuts, etc., are usually independent small- and medium- sized companies. Such a hierarchical structure can be ascertained from Fig. 2.

An interesting observation is that Hyundai Mobis, a module component supplier, is as distinctive as the auto-makers. Hyundai Mobis plays a key role in the Hyundai-Kia Motor Group and is recognized as the key driver of productivity and innovation. The graph seems to reflect this reality. Mando and Delphi, key module and system component manufacturers for Hyundai-Kia and GM, respectively, also have high visibility in the graph. This is also a reflection of the reality that auto makers have moved toward module-based production.

One of the most commonly used social network analysis metrics is degree centrality, 
which measures the number of direct ties to a node. Degree centrality can be interpreted as operational load and influential scope [2,11]. The degree centrality results of both directed and undirected networks were similar, as summarized in Table 1. Companies that showed a high degree centrality were mostly auto-makers or part manufacturers belonging to the Hyundai-Kia Motor Group. Kim et al. [11] argued that companies having high degree centrality in undirected network are the ones having strong influence on others. Considering the influence of Hyundai-Kia Motor Group on the South Korean automotive industry, this argument seems to be validated and the result shows the degree of power concentration in the South Korean automotive industry. In addition, the degree centrality of GM and Delphi was higher than its operational scale in South Korea. This result indicates that the importance of the GM group in the South Korean automotive industry may be under-estimated; and also shows the possibility of using SNA to discover new perspectives in the supply chains.

Table 1. List of companies having high degree centrality

\begin{tabular}{|c|c|c|c|c|c|}
\hline \multicolumn{3}{|c|}{ In-degree centraility (supply load) } & \multicolumn{3}{|c|}{ Degree centrality (influential scope) } \\
\hline Rank & Company & Value & Rank & Company & Value \\
\hline 1 & Hyundai Motor & 196 & 1 & Hyundai Motor & 196 \\
\hline 2 & Kia Motor & 173 & 2 & Kia Motor & 173 \\
\hline 3 & GM & 125 & 3 & GM & 125 \\
\hline 4 & Hyundai Mobis & 67 & 4 & Hyundai Mobis & 72 \\
\hline 5 & Ssangyong Motor & 43 & 5 & Ssangyong Motor & 43 \\
\hline 6 & $\begin{array}{l}\text { Renault-Samsung } \\
\text { Motors }\end{array}$ & 28 & 6 & $\begin{array}{l}\text { Renault-Samsung } \\
\text { Motors }\end{array}$ & 28 \\
\hline 7 & Mando & 14 & 7 & Mando & 20 \\
\hline 8 & Delphi & 12 & 8 & Hyundai Wia & 14 \\
\hline 8 & Hyundai Wia & 12 & 9 & Delphi & 12 \\
\hline 8 & Hyundai Powertech & 12 & 9 & Hyundai Powertech & 12 \\
\hline & & & 9 & Hyundai Dymos & 12 \\
\hline
\end{tabular}

Another one of the most commonly used social network analysis metrics is betweenness centrality, which measures the frequency of a node that appears on the shortest path between a pair of other nodes[7,8]. In the social network context, the betweenness is interpreted as the degree of gate-keeping that a node does for the other nodes.

The results of betweenness centrality were different in directed and undirected network, as can be seen in Table 2. In the directed network model of supply network, two major first-tier suppliers of the Hyundai-Kia Motor Group, Hyunidai Mobis and Mando, showed the highest betweenness centrality. Companies with high betweenness centrality in the directed network model were key manufacturers of various parts, such as S\&T Dynamics (powertrain components), Daewon Indusrty (car seat), Namyang Industry (steering and braking system), Central (steel rods), Yuratech (spark plugs), Halla-Visteon (climate control system), and Magna Powertrain Korea (pumps). Some of these companies (e.g. Halla-Visteon, Magna Powertrain Korea) were large-sized companies whereas others are medium sized companies. 
In an undirected network model, the list of companies with high between-ness centrality was similar to the companies having high degree centrality. Kim et al.[11] argued that betweenness centrality in directed network indicates operational criticality, whereas betweenness centrality in undirected network is related to the role of mediating relations. When applying that argument to a result, the operational criticality argument for directed network seems to be validated, whereas the relational mediation argument appears to need further verification and refinement. In addition, the result suggests that in automotive supply network, key parts and suppliers are widely distributed to various parts beside key module components.

In terms of the number of units produced in South Korea, GM's proportion(15.1\%) of the South Korean automotive industry is greater than SsangYong (6.4\%) and RenaultSamsung (6\%) but is significantly smaller than Hyundai-Kia(76\%). However, in terms of degree centrality and betweenness centrality, GM's significance in the South Korean automotive supply network seems to be more than what is suggested by the number of produced units [10]. SssangYong and Renault-Samsung are similar in terms of the number of produced units. However, SsangYong showed higher between-ness centrality than Renault-Samsung in the directed network model, whereas RenaultSamsung's between-ness in the undirected network was higher than SsangYong's. Based on the theoretical framework of Kim et al. [12], that fact can be interpreted to mean SsangYong is more operationally critical than Renault-Samsung, whereas Renault-Samsung has a greater potential to connect separated groups of suppliers. This new insight seems to make sense, yet it needs further investigation.

Table 2. List of companies having high betweenness centrality

\begin{tabular}{|c|c|c|c|c|c|}
\hline \multicolumn{3}{|c|}{$\begin{array}{l}\text { Between-ness centrality in directed network } \\
\text { (operational criticality) }\end{array}$} & \multicolumn{3}{|c|}{$\begin{array}{l}\text { Between-ness centrality in undirected network } \\
\text { (relational mediation) }\end{array}$} \\
\hline Rank & Company & Value & Rank & Company & Value \\
\hline 1 & Hyundai Mobis & 228.0 & 1 & Hyundai Motor & 30088.4 \\
\hline 2 & Mando & 52.5 & 2 & Kia Motor & 19725.3 \\
\hline 3 & Hyundai Dymos & 40.3 & 3 & GM & 19075.0 \\
\hline 4 & S\&T Dynamics & 21.2 & 4 & Hyundai Mobis & 7488.1 \\
\hline 5 & $\begin{array}{l}\text { Halla Visteon } \\
\text { Climate Control }\end{array}$ & 18.2 & 5 & $\begin{array}{l}\text { Renault-Samsung } \\
\text { Motors }\end{array}$ & 5583.5 \\
\hline 6 & Daewon & 11.5 & 6 & Mando & 3720.6 \\
\hline 7 & $\begin{array}{l}\text { Magna } \\
\text { Korea }\end{array}$ & 10.8 & 7 & Hanjoo Metal & 3477.0 \\
\hline 8 & Namyang Industries & 9.0 & 8 & Ssangyong Motor & 3128.4 \\
\hline 9 & Central & 8.5 & 9 & Hyundai Dymos & 2422.6 \\
\hline 10 & Yura Tech & 6.0 & 10 & Delphi & 2393.9 \\
\hline
\end{tabular}

Closeness centrality, calculated by the average of the minimal length to the other nodes, is also one of the most commonly used social network analysis metrics[7,8]. Nine companies displayed high closeness centrality in the supply network are shown in Table 3. These companies can be classified into the following three types: 1) auto manufacturers(Hyundai, Kia, GM), 2) key module suppliers(Hyundai Mobis, Mando), 
and 3) companies providing commodity like products (Continental Automotive Electronics, Taeyang Metal, Youngsin Metal, Youngshin Precision) to many companies. Kim et al.[11] argued that companies with higher closeness centrality are those who can act autonomously and navigate freely across the network to access resources in a timely manner. This result confirms that those kinds of companies seem to be independent. But it seems what allows the companies to access information and resources is not just closeness but the nature of the relationships with key companies.

Table 3. List of companies having high closeness centrality (undirected network)

\begin{tabular}{|c|l|r|}
\hline Rank & \multicolumn{1}{|c|}{ Company } & \multicolumn{1}{|c|}{ Value } \\
\hline 1 & Hyundai Motor & 1.9 \\
\hline 2 & Kia Motor & 2.0 \\
\hline 3 & GM & 2.2 \\
\hline 4 & Hyundai Mobis & 2.3 \\
\hline 5 & Mando & 2.4 \\
\hline 5 & Continental Automotive Electronics & 2.4 \\
\hline 7 & Taeyang Metal & 2.5 \\
\hline 7 & Youngsin Metal & 2.5 \\
\hline 7 & Youngshin Precision & 2.5 \\
\hline
\end{tabular}

\section{Conclusion}

It is difficult to obtain knowledge on an industry structure and dynamics through an analysis focusing on individual companies. Using the SNA approach to analyze the supply network, it was possible to better understand the structure of the South Korean automotive industry. This study confirms the potential of the SNA approach as applied to supply network studies. However, it should be noted that prior domain knowledge, as well as SNA-based analysis, on the industry helped in reaching an understanding. In this sense, the SNA methods seem to be useful in confirmatory as well as exploratory studies.

One limitation of this paper is the data. As stated earlier, most major South Korean companies in the automotive industry were included in the data. However, many South Korean companies are suppliers for overseas companies and the complete supply network of those overseas companies was not included in the data that were analyzed. Considering the trend of rapid globalization, the structure and operation of the companies belonging to overseas supply networks may affect the structure and operations of the South Korean companies. Also, because some companies that are primarily in other industries, such as electronics, are not members of Korean Auto Industries Cooperative Association (KAICA), they are not included in the supply network, which was analyzed in this research. Considering the trend of the ITautomobile convergence, the analysis may have missed some important IT companies that are critical to automotive industry.

Another limitation of this research stems from the characteristics of SNA methodologies. Important aspects of business relationships, such as intensity of 
relationships and scale of transactions, are hard to model as social networks. This research regarded those relationships as all being equal. Of course, by modeling the relationship this way, it is possible to obtain a new perspective from the analysis. However, especially from the practitioner's perspective, this may be considered as a significant barrier to applying the SNA to real industry examples. As Park [15] pointed out, SNA methods are not robust against sampling. Unlike typical statistical analysis where samples are generally independent, entities in the social network are all linked with each other and affect the result of analysis. Hence, to obtain unbiased results, the complete network needs to be modeled and analyzed.

The biggest contribution of this research to the literature is that this is the first trial on applying SNA methods to large-scale supply networks and the entire automotive supply chains of a country. Despite the limitations stated above, by building a relative large social network model containing most major South Korean automotive companies and by using a previously validated framework for the interpretation of SNA metrics in the supply network context, we believe that the results of this study have credibility.

In this study, the focus was on analyzing the overall South Korean automotive industry. As for future research, comparative research on the supply networks of Hyundai Motor and Kia Motor and other companies will be performed. A comparison of the South Korean automotive companies and Japanese automotive companies may also be an interesting future research topic.

\section{References}

1. Autry, C.W., Griffis, S.E. 2008. Supply chain capital: the impact of structural and relational linkages on firm execution and innovation. Journal of Business Logistics 29(1), pp.157-174

2. Borgatti, S.P., Li, X. 2009. On social network analysis in a supply chain context. Journal of Supply Chain Management 45 (2), pp. 5-21.

3. Carter, C.R., L.M. Ellram, W. Tate, 2007. The use of social network analysis in logistics research. Journal of Business Logistics 28 (1), pp.137-169

4. Choi, T.Y., Dooley, K.J., Rungtusanatham, M., 2001. Supply networks and complex adaptive systems: control versus emergence. Journal of Operations Management, 19 (3), pp.351-366

5. Choi, T.Y., Y. Hong, 2002. Unveiling the structure of supply networks: case studies in Honda, Acura, and DaimlerChrysler. Journal of Operations Management 20 (5), pp. 469-493

6. Choi, T.Y., Kim, Y. 2008. Structural embededness and supplier management: a network perspective. Journal of Supply Chain Management 44 (4), pp.5-13.

7. Everett, M.G., Borgatti, S.P., 1999. The centrality of groups and classes. Journal of Mathematical Sociology 23 (3), 181-201.

8. Freeman, L.C., 1979. Centrality in social networks: conceptual clarification. Social Networks 1, 215-239. 
9. Harland, C.M., Lamming, R.C., Zheng, J., Johnsen, T.E., 2001. A taxonomy of supply networks. The Journal of Supply Chain Management 37 (4), pp.21-27

10. KARI (Korea Automotive Research Institute), 2014. 2014 Korean Automotive Industry.

11. Kim, C., Jo. H.J., Jeong, 2011. J.H. Modular Production and Hyundai Production System : The Case of Hyundai MOBIS, Economy and Society, Vol. 92, pp. 351-385 (Korean Manuscript)

12. Kim, Y., T. Y. Choi, T. Yan, K. Dooley, 2011. Structural investigation of supply networks: a social network approach, Journal of Operations Management, Vol. 29, pp.194-211

13. Kim, W.S. 2009. Effects of a trust mechanism on complex adaptive supply networks: an agent-based social simulation study. Journal of Artificial Societies and Social Simulation, 12(3), p.4

14. Lamming, R.C., Johnsen, T.E., Zheng, J., Harland, C.M., 2000. An initial classification of supply networks. International Journal of Operations and Production Management, 20 (6), pp.675-691.

15. Park. S.J. 2011. Social Network Analysis for Smart Business. KORMS 2011 Spring Conference Tutorial

16. Pathak, S.D., Day, J.M., Nair, A., Sawaya, W.J., Kristal, M.M., 2007. Complexity and adaptivity in supply networks: building supply network theory using a complex adaptive systems perspective. Decision Sciences 38 (4), pp.547-580.

17. Surana, A., Kumara, S., Greaves, M., Raghavan, U.N., 2005. Supply chain network: a complex adaptive systems perspective. International Journal of Production Research, 43, pp. 4235-4265. 